\title{
Endovascular and surgical treatment of spinal dural arteriovenous fistulas
}

\author{
Robert H. Andres • Alain Barth • Raphael Guzman • \\ Luca Remonda • Marwan El-Koussy • Rolf W. Seiler • \\ Hans R. Widmer • Gerhard Schroth
}

Received: 3 March 2008 / Accepted: 8 June 2008 / Published online: 28 June 2008

(C) Springer-Verlag 2008

\begin{abstract}
Introduction The aim of this retrospective study was to evaluate the clinical outcome of patients with spinal dural arteriovenous fistulas (SDAVFs) that were treated with surgery, catheter embolization, or surgery after incomplete embolization.

Methods The study included 21 consecutive patients with SDAVFs of the thoracic, lumbar, or sacral spine who were treated in our institution from 1994 to 2007. Thirteen patients were treated with catheter embolization alone. Four patients underwent hemilaminectomy and intradural interruption of the fistula. Four patients were treated by endovascular techniques followed by surgery. The clinical outcome was assessed using the modified Aminoff-Logue scale (ALS) for myelopathy and the modified Rankin scale (MRS) for general quality of life. Patient age ranged from 44 to 77 years (mean 64.7 years).
\end{abstract}

R. H. Andres · A. Barth · R. Guzman • R. W. Seiler •

H. R. Widmer

Department of Neurosurgery, University of Berne, Inselspital,

Berne, Switzerland

R. H. Andres · L. Remonda • M. El-Koussy $\cdot$ G. Schroth Department of Diagnostic and Interventional Neuroradiology, University of Berne, Inselspital,

Berne, Switzerland

A. Barth

Department of Neurosurgery, Medical University of Graz,

Graz, Austria

R. H. Andres $(\bowtie) \cdot$ R. Guzman

Department of Neurosurgery, Stanford University Medical Center,

1201 Welch Road, MSLS P304,

Stanford, CA 94305-5487, USA

e-mail: randres@stanford.edu
Results Surgical as well as endovascular treatment resulted in a significant improvement in ALS (-62.5\% and $-31.4 \%$, respectively, $p<0.05)$ and a tendency toward improved MRS ( $-50 \%$ and $-32 \%$, respectively) scores. Patients that underwent surgery after endovascular treatment due to incomplete occlusion of the fistula showed only a tendency for improvement in the ALS score $(-16.7 \%)$, whereas the MRS score was not affected.

Conclusion We conclude that both endovascular and surgical treatment of SDAVFs resulted in a good and lasting clinical outcome in the majority of cases. In specific situations, when a secondary neurosurgical approach was required after endovascular treatment to achieve complete occlusion of the SDAVF, the clinical outcome was rather poor. The best first line treatment modality for each individual patient should be determined by an interdisciplinary team.

Keywords Dural arteriovenous fistula $\cdot$ Spine $\cdot$ Treatment . Surgery $\cdot$ Embolization

\section{Introduction}

Spinal dural arteriovenous fistulas (SDAVFs) are rare pathological entities consisting of an arteriovenous shunt between one ore more branches of a dural artery and the medullary venous system. The fistula is usually located in the dura of the nerve root and/or adjacent spinal dura and fed by a dural branch of the corresponding segmental radicular artery. The drainage is accomplished by a medullary vein, which leads to retrograde filling of the coronal vein plexus, resulting in its congestion and dilatation. The venous hypertension with a reduced pressure gradient finally causes reduced perfusion, ischemia, and 
edema of the spinal cord, typically leading to a slowly progressive congestive myelopathy $[1,2]$. Clinically, the disease usually presents with progressive gait disturbance as well as numbness and paresthesia of the lower extremities [3]. However, radiculopathy and rarely subarachnoid hemorrhage have also been reported to occur in the context of SDAVFs [4, 5]. The frequently observed discrepancy between the location of the SDAVF and the spinal level responsible for clinical symptoms suggests that the symptoms might be primarily depend on the venous drainage $[6,7]$.

SDAVFs account for about $70 \%$ of spinal arteriovenous malformations (AVM), with an annual incidence of five to ten cases per million [8]. There is a strong gender predisposition in males (about $80 \%$ ) with an average age of 62 years at onset of clinical symptoms [9]. The pathogenesis of SDAVFs remains unclear. The middle-age onset suggests an acquired condition, unlike intradural arteriovenous fistulas or intramedullary AVM, which are considered to represent congenital malformations [10, 11]. In contrary to intracranial dural arteriovenous fistulas, SDAVFs are not associated with thrombophilia [12]. Metachronous double SDAVFs can be a rare problem in the management of the disease [13].

Due to the low incidence and the nonspecific symptomatology, an appropriate diagnostic workup is often not performed, and the time to diagnosis is long. In a large series of 66 patients, the average time from symptoms onset to diagnosis was reported to be 27 months [9]. Late diagnosis is problematic, as the condition can be treated and recovery after surgical and/or endovascular treatment is good [3].

Magnetic resonance (MR) imaging of the whole spine is the screening procedure of choice and has replaced myelography. Typical MR findings include spinal cord signal hyperintensity in T2-weighted images, enlargement of the spinal cord, and dilatation of the perimedullary veins. Radiological findings frequently disappear after treatment and are often correlated with clinical symptoms [14]. A recent report suggested that diffusion-weighted imaging and apparent diffusion coefficient maps might be useful to identify the vasogenic edema caused by SDAVFs [15]. Contrast-enhanced MR angiography [16-18] and multislice computerized tomographic (CT) angiography [19] may facilitate the diagnostic procedure. However, if an SDAVF is suspected, a selective multilevel spinal catheter angiography is required to confirm the diagnosis and determine the exact feeder location and vascular anatomy of the fistula.

Due to the low incidence of the disease, only limited data on the management of these patients are available. Treatment options for SDVAF include endovascular and microsurgical occlusion of the fistula. The surgical treat- ment consists of intradural interruption of the draining vein at the fistula point [20]. Alternatively, endovascular treatment with selective catheter embolization is possible [21]. Endovascular therapy as opposed to open surgery is a less invasive treatment choice and can usually be performed in the same session as diagnostic angiography. Whether or not these advantages are counterbalanced by a lower recanalization rate and therefore a better long-term outcome after surgical treatment remains a matter of debate. Although several studies have reported good and lasting results for both therapeutic strategies, a meta-analysis based on the data from 16 surgical and ten endovascular studies favored surgical treatment [22]. However, the decision between endovascular and surgical treatment remains a controversially discussed topic in the current literature [23], and further investigations are necessary to clarify this issue.

The present study assessed the clinical outcome of 21 patients with SDAVFs treated at our institution with surgery, catheter embolization or surgery after embolization during the last 12 years.

\section{Materials and methods}

The series consisted of 21 patients with dural fistulas of the thoracic, lumbar, or sacral spine that were treated in our institution, which is a large third-level neurovascular center in Switzerland, from 1994 to 2007. Patient age ranged from 44 to 77 years (mean 64.7 years) and included five female (24\%) and 16 male (76\%) subjects. All patients underwent diagnostic workup with MR imaging of the whole spinal cord for screening and consecutive selective spinal angiography, which confirmed the presence of an SDAVF in all cases. Diagnostic and interventional angiography was performed on a biplane digital subtraction angiography unit (CAS 500; Toshiba Medical Systems, Tokyo, Japan).

Patients underwent diagnostic angiography and embolization under local anesthesia using the transfemoral approach. Depending on the origin of the feeding arteries, various pre-shaped catheters with an inner diameter of 0.97 $\mathrm{mm}$ were used for spinal angiography (Spinal Super Torque, Johnson \& Johnson, Division Cordis, Switzerland). Before the diagnostic or interventional procedure, the diameter of the aorta was measured, based on the MR or CT image. Depending on the aortic diameter, one of three different catheter sizes (Berner Spinalkatheter I-III: 10, 13, or $16 \mathrm{~mm}$ ) was chosen to get optimal stability during the intervention [24]. The angiographic protocol included catheterization of the vertebral and segmental arteries, including the lower lumbar arteries, median and lateral sacral arteries, and internal iliac arteries for lower lumbar or sacral lesions. Selective angiography of the suspected feeding arteries was then performed. For embolization, a 
1:5 mixture of $n$-butylcyanoacrylate (Histoacryl, B. Braun Melsungen AG, Melsungen, Germany) and iodized oil (Lipiodol Ultra-Fluid, Guerbet, Aulnay-sous-Bois, France) with added tantalum powder was injected via a microcatheter (Fast Tracker 10, Target Therapeutics, Fremont, CA, USA) coaxially inserted through the guiding catheter (Fig. 1).

A decision to treat was made in all patients with angiographically confirmed diagnosis of SDAVF. In the same angiographic session, an attempt to embolization was made in all patients where the lesion seemed favorable for endovascular treatment with a reasonable risk $(n=17)$. Exclusion criteria included severe arteriosclerosis, arterial feeders too small to catheterize, and common origin of the great radicular artery of Adamkiewicz from the same segmental artery as the feeding artery of the fistula [25]. In these cases $(n=4)$, the decision for surgical treatment was made after diagnostic angiography. These patients underwent hemilaminectomy and microsurgical intradural interruption of the draining vein by clipping and/or coagulation under general anesthesia (Fig. 2). In a small number of selected cases $(n=3)$, endovascular treatment was repeated one time due to partial fistula occlusion after the first session and configuration of the fistulas that favored endovascular treatment. Clinical symptoms were assessed before and after treatment using the modified AminoffLogue grading scale (ALS) for myelopathy (Table 1) [26] and the modified Rankin scale (MRS) [27]. Patients underwent clinical examination at $1,3,6$, and 12 months after treatment and every 6 months thereafter. Spinal MR imaging was carried out at 1 month after treatment. Prompt angiographic reevaluation was performed in patients without clinical improvement after treatment or in case of secondary deterioration. Follow-ups were available with a median of 26 months (range 12 to 42 months) after treatment. All statistical analyses were carried out using a commercially available software package (GraphPad Instat 3.0, GraphPad Software, San Diego, CA, USA). The patient groups were compared using the nonparametric Kruskal-Wallis test followed by Dunn's multiple comparisons post hoc analysis. The statistical significance level was set at $p<0.05$. Values are presented as mean \pm SEM.
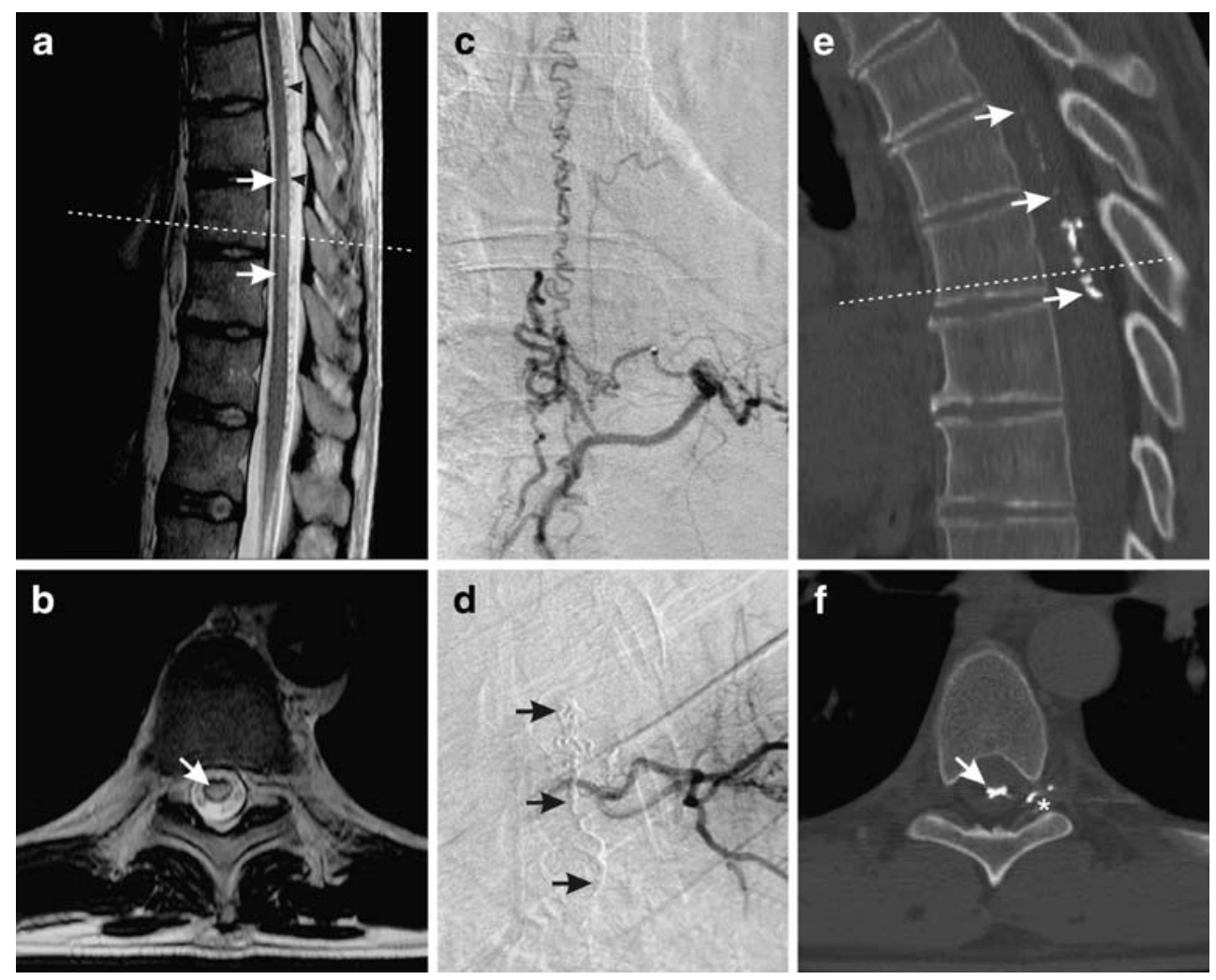

Fig. 1 Endovascular treatment of a dural arteriovenous fistula with a feeder on level D6 (patient \#18). Preinterventional T2-weighted sagittal (a) and axial (b) MR sequences showed a prominent medullar edema (arrows) on the level of D8 to D11 and dilated vascular structures presenting with flow void (arrowheads) in the perimedullar intradural space. Spinal angiography with selective catheterization of the left segmental artery D6 revealed a dural arteriovenous fistula on this level with rostral drainage (c). After embolization using a histoacryl/lipiodol mixture with added tantalum powder, no residual perfusion of the fistula could be demonstrated anymore (arrows, d). The post-interventional CT scan confirmed the obliteration of the pathological feeding vessels in the left neuroforamen D6/7 (asterisk) and the perimedullar draining veins (arrows) by tantalum-containing embolization material $(\mathbf{e}, \mathbf{f})$. The dashed line on sagittal images indicates the level of axial sections 

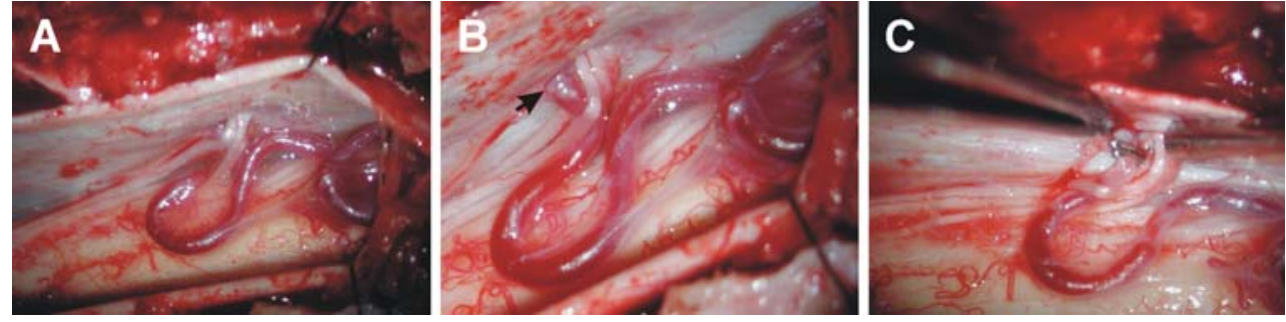

Fig. 2 Surgical technique of occlusion of a dural arteriovenous fistula (patient \#11). After a right hemilaminectomy of D7-8 and exposure of the dural sac, the dura is microsurgically opened with a linear paramedian incision (a). Pathologic tortuous draining vessels of the fistula are exposed, and the fistula point is identified at the level of D7 as the feeding artery enters the intradural space (b, arrow). At this point, the draining vessel is closed by application of two clips and bipolar coagulation (c). Successful occlusion of the fistula results in immediate darkening of the blood in the draining vein

\section{Results}

A total of 21 consecutive patients (five women and 16 men) that underwent surgery and/or endovascular treatment of SDAVFs in our institution between 1995 and 2007 were retrospectively included in the study (Table 2). All patients with the exception of one subject suffering from lumbar back pain as the sole symptom presented with clinical signs of myelopathy with different grades. The mean ALS score at admission was $4.9 \pm 0.5$, whereas the mean MRS score was $2.9 \pm 0.3$. None of the patients presented with signs of hemorrhage, which is consistent with the low incidence of bleeding from SDAVFs reported in the literature [5, 28]. All patients underwent selective spinal angiography, which confirmed an SDAVF of the thoracic $(n=11)$, lumbar $(n=$ $7)$, or sacral $(n=3)$ spine. In accordance with other studies, the majority of the SDAVFs in our series were located in the lower thoracic or lumbar region [29], and the welldocumented strong male preponderance was also observed in our patient collective [18].

Patients treated by surgery alone showed a significant improvement in the ALS (4.8 \pm 0.8 before and $1.8 \pm 0.3$ after treatment, respectively, $p<0.05)$ and a tendency for improvement in the MRS $(3.0 \pm 0.7$ before and $1.5 \pm 0.3$ after treatment, respectively, $p=0.11$ ) scores. Patients treated by embolization alone also showed significantly improved ALS (5.1 \pm 0.7 before and $3.5 \pm 0.5$ after treatment, respectively, $p<0.05)$ and a tendency for lower MRS $(3.15 \pm 0.4$ before and $2.15 \pm 0.3$ after treatment, respectively, $p=0.08$ ) scores. Patients that underwent surgical and endovascular treatment due to incomplete occlusion of the fistula after embolization showed only a trend toward improvement in the ALS score ( $4.8 \pm 1.4$ before and $4.0 \pm 1.7$ after treatment, respectively), whereas the MRS values were not changed ( $2.25 \pm 0.3$ before and $2.25 \pm 0.8$ after treatment, respectively). The results expressed as percentages of the preinterventional values are presented in Fig. 3.

In four out of 17 cases that were primarily selected for endovascular treatment in this study, the SDAVF could not definitely be occluded by this technique, representing a failure rate of $23.5 \%$.

There were no significant differences in the patient age and in the pre-interventional ALS and MRS score values between the surgical, endovascular, and surgical/endovascular treatment groups.

\section{Discussion}

Due to the unspecific presentation of initial symptoms in combination with a usually slow progression of the rare disease, the diagnosis of an SDAVF remains difficult based on clinical suspicion. With an annual incidence of five to ten per million in the Western population [30], the estimated number of newly developing cases in Switzerland each year is about 35-70 cases. Due to the coverage of about $20 \%$ of the neurovascular cases in Switzerland by our institution, it can be estimated that 7-14 patients with SDAVFs should be admitted per year. The number of 21 patients treated at our institution during the last 12 years suggests a significant underdiagnosis and undertreatment of patients with SDAVFs. This notion is particularly of

Table 1 Modified ALS for the assessment of myelopathy

Modified ALS

\begin{tabular}{cl}
\hline Gait & \\
0 & Normal \\
1 & Leg weakness, abnormal gait or stance, \\
& but no restriction of activity \\
2 & Restricted activity \\
3 & Requiring one stick for walking \\
4 & Requiring two sticks, crutches, or walker \\
5 & Confined to wheelchair \\
Micturation & \\
0 & Normal \\
1 & Hesitancy, frequency, urgency \\
2 & Occasional urinary incontinence or retention \\
3 & Total incontinence or persistent retention
\end{tabular}


Table 2 List of patients

\begin{tabular}{|c|c|c|c|c|c|c|c|c|c|c|c|}
\hline Pat \# & Age & Sex & Location & Side & Drainage & Treatment & Symptoms & $\begin{array}{l}\text { ALS } \\
\text { pre }\end{array}$ & $\begin{array}{l}\text { ALS } \\
\text { post }\end{array}$ & $\begin{array}{l}\text { MRS } \\
\text { pre }\end{array}$ & $\begin{array}{l}\text { MRS } \\
\text { post }\end{array}$ \\
\hline 1 & 67 & M & D6 & Left & Caudal & Surgical & $\begin{array}{l}\text { Paraparesis, paresthesia, } \\
\text { anuresis }\end{array}$ & 6 & 2 & 5 & 2 \\
\hline 2 & 67 & M & D6 & Right & Caudal + rostral & Endovascular $(2 \mathrm{x})$ & Spastic paraparesis & 2 & 3 & 2 & 3 \\
\hline 3 & 57 & M & D5 & Right & Caudal & Both & Spastic paraparesis, ataxia & 3 & 1 & 2 & 1 \\
\hline 4 & 68 & M & L1 & Left & Rostral & Endovascular & $\begin{array}{l}\text { Severe paraparesis, paresthesia, } \\
\text { incontinence }\end{array}$ & 6 & 4 & 5 & 4 \\
\hline 5 & 59 & M & D6 & Left & Caudal & Surgical & Atactic gait disorder, incontinence & 3 & 1 & 2 & 1 \\
\hline 6 & 76 & $\mathrm{~F}$ & L2 & Right & Caudal & Endovascular & $\begin{array}{l}\text { Spastic paraparesis, paresthesia, } \\
\text { incontinence }\end{array}$ & 6 & 4 & 3 & 2 \\
\hline 7 & 57 & $\mathrm{~F}$ & L1 & Right & Caudal & Both & Paresthesia & 2 & 1 & 2 & 1 \\
\hline 8 & 56 & M & $\mathrm{S} 2$ & Both & Rostral & Endovascular & Severe paraparesis, incontinence & 7 & 7 & 4 & 4 \\
\hline 9 & 74 & M & D7 & Left & Caudal & Both & Paraparesis, paresthesia & 6 & 7 & 2 & 3 \\
\hline 10 & 45 & M & D8 & Left & Caudal & Endovascular & Spastic paraparesis, ataxia & 3 & 2 & 1 & 1 \\
\hline 11 & 76 & $\mathrm{M}$ & D7 & Right & Caudal & Surgical & $\begin{array}{l}\text { Spastic paraparesis, paresthesia, } \\
\text { incontinence }\end{array}$ & 6 & 2 & 2 & 1 \\
\hline 12 & 75 & M & D8 & Right & Caudal & Endovascular & Severe paraparesis, anuresis & 7 & 5 & 4 & 3 \\
\hline 13 & 52 & $\mathrm{~F}$ & $\mathrm{~S} 2$ & Right & Rostral & Endovascular & Low back pain & 2 & 2 & 2 & 2 \\
\hline 14 & 75 & M & D7 & Right & Rostral & Surgical & Paraparesis, incontinence & 4 & 2 & 3 & 2 \\
\hline 15 & 77 & M & D6 & Left & Caudal & Endovascular & $\begin{array}{l}\text { Atactic gait disorder, } \\
\text { paresthesia, pain }\end{array}$ & 3 & 2 & 2 & 1 \\
\hline 16 & 70 & M & L1 & Left & Rostral & Both & Severe paraparesis, incontinence & 8 & 7 & 3 & 4 \\
\hline 17 & 63 & M & L3 & Right & Rostral & Endovascular $(2 \mathrm{x})$ & Severe paraparesis, cauda lesion & 8 & 6 & 4 & 3 \\
\hline 18 & 44 & M & D6 & Left & Rostral & Endovascular & $\begin{array}{l}\text { Spastic paraparesis, ataxia, } \\
\text { incontinence }\end{array}$ & 4 & 2 & 3 & 1 \\
\hline 19 & 73 & $\mathrm{~F}$ & L3 & Right & Caudal & Endovascular & $\begin{array}{l}\text { Severe paraparesis, cauda syndrome, } \\
\text { anuresis }\end{array}$ & 8 & 2 & 5 & 1 \\
\hline 20 & 61 & M & S2 & Right & Rostral & Endovascular $(2 \mathrm{x})$ & $\begin{array}{l}\text { Atactic gait disorder, paresthesia, } \\
\text { incontinence }\end{array}$ & 2 & 1 & 1 & 1 \\
\hline 21 & 67 & $\mathrm{~F}$ & L3 & Left & Rostral & Endovascular & Severe paraparesis, anuresis & 8 & 6 & 5 & 2 \\
\hline
\end{tabular}

importance, as $50 \%$ of untreated patients become disabled within 3 years $[26,31,32]$. Nevertheless, the number in the present study is consistent with those from other reports in countries with comparable healthcare systems [8, 33, 34]. Hence, we suggest that, even if the symptoms are

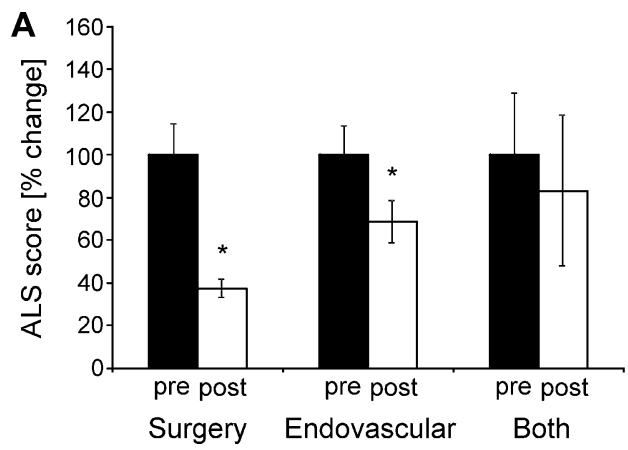

Fig. 3 Clinical outcome of surgical, endovascular and surgical after endovascular treatment of SDAVFs. The severity of myelopathic symptoms was graded using the modified Aminoff-Logue scale $(A L S$, a), whereas general quality of life was assessed using the modified Rankin scale $(M R S, \mathbf{b})$. Surgical and endovascular treatment both resulted in significantly improved ALS and a tendency for improved unspecific, the threshold for performing diagnostic workup in case of suspicion of an SDAVF should be lower than practiced today.

As reported in the literature, treatment by permanent occlusion of SDAVFs results in clinical improvement in

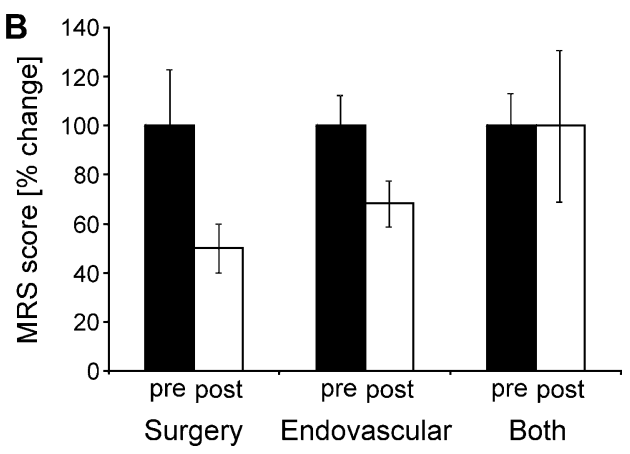

MRS scores, whereas patients treated with surgery after primary embolization (both) showed no significant clinical improvement in the ALS and MRS scores. Data are expressed as percentage of pretreatment values and given as mean \pm SEM. Asterisk indicates significant differences $(p<0.05)$ vs. pretreatment values 
$70 \%$ of cases [8]. The success of treatment depends on definitive interruption of the draining vein and not the arterial feeders, because otherwise the fistula has the tendency to re-establish flow by recruiting new arterial feeding vessels, resulting in clinical recurrence [35].

However, there exists some controversy on the choice of treatment modalities for SDAVFs. Some authors favor surgical treatment [36-39], whereas others recommend endovascular embolization [21, 40, 41]. A meta-analysis of 16 surgical studies by Steinmetz et al. [22] has demonstrated successful occlusion of the SDAVF in $98 \%$ of the cases with a morbidity of less than $2 \%$ and no mortality. Clinical improvement was found in $55 \%$ and stabilization of the clinical condition in $34 \%$ of the surgically treated patients, respectively. Data from the same meta-analysis on ten endovascular therapy studies showed that embolization resulted in initial occlusion of the fistula in $46 \%$ of cases with a morbidity of less than $4 \%$ and an absence of mortality. Due to the heterogeneity and insufficient longitudinal data of endovascular studies, a comparison between the clinical efficacy of surgery and catheter embolization by meta-analysis was not possible. In a single center series, neurological improvement in patients treated with embolization alone was reported in $44 \%$ and stabilization of the clinical condition in 56\% [42]. Due to the superior results using surgery as compared to embolization, Steinmetz and collaborators recommended surgical treatment as the first-line therapy in dealing with SDAVFs.

On the other hand, experience and techniques in interventional neuroradiology have constantly evolved during the last decade, and a more recent report has shown permanent occlusion of the fistula and a corresponding improvement of neurological deficits in $81 \%$ of endovascularly treated patients [43]. Another study reported a low recurrence rate of $10.5 \%$ after embolization of SDAVFs and significant improvements in ALS and Karnofsky performance status scores after a mean clinical follow-up period of more than 100 months [23]. Based on their experience with endovascular treatment, two other groups advocate an attempt at embolization after diagnostic angiography and recommend surgery if endovascular treatment fails [44, 45].

Surgery should be considered in cases in which selective introduction of the microcatheter is difficult, Adamkiewicz's artery or the anterior spinal artery originates from the feeding radicular artery, multiple small feeding arteries are present, recurrence occurred after embolization, or a previous embolization attempt was incomplete [46]. In our series, the decision for surgical treatment was made according to these criteria with the exception of three cases in which a second attempt at endovascular treatment was made after initial incomplete embolization or recurrence because of angiographic findings very favorable for re-embolization. All patients that underwent a primary surgical intervention showed robust recovery of neurological symptoms, and the complication rate was zero. These results are in line with another series of 21 patients, where Huffmann et al. [36] reported complete occlusion of the lesions in all patients and only a minor complication rate with each one case of transient neurological deterioration, local cerebrospinal fluid accumulation, and wound healing problems.

Endovascular treatment has the advantage of minor invasiveness and can be performed in a single setting after diagnostic angiography, but occlusion rates are still lower than in surgical treatment [8]. Due to the lower recanalization rate, liquid embolic agents, such as cyanoacrylates, are preferred to polyvinyl alcohol particles for embolization [8, 47]. In contrast to particles, liquid glue may reach the nidus of the dural fistula and can penetrate into the venous side, leading to occlusion of the fistula [48]. If a tantalum-containing embolization mixture is used, a spinal CT scan can be performed to document the correct intradural localization of the embolization material immediately after the intervention (Fig. 2e-f), which has been previously reported to correlate with the absence of fistula recanalization and with clinical improvement [43, 49]. In addition, the tantalum particles may be helpful for intra-operative radiographic localization of the SDAVF if there is need for surgical treatment later [50]. After endovascular treatment, short-term clinical control examinations are necessary to exclude recurrence of the fistula due to collaterally reestablished flow in a possibly non-occluded spinal cord vein. If an angiographic follow-up is not performed on a regular basis, prompt angiographic reevaluation is mandatory in case of poor clinical recovery or secondary deterioration to prevent delayed treatment with possibly progressive disease [25].

The reasons for the poor outcome in the four patients that required secondary surgical treatment after endovascular therapy failed are not clear. In three cases, the fistula could not be completely occluded by endovascular treatment due to the configuration of the fistula (patients \#7 and \#16) and due to vasospasm (patient \#9). These patients were immediately scheduled for surgical treatment within the next weeks. One case (\#3) with complete radiological occlusion of the SDAVF and a favorable initial outcome after embolization showed clinical deterioration within 3 months and underwent surgical interruption of the fistula a few weeks later. As all patients presented with a history of myelopathic symptoms for several months, we do not think that the additional delay due to the endovascular treatment attempt is responsible for the poor outcome in this group. However, although there have been no significant differences in the severity of the initial clinical presentation between the different treatment groups, it is possible that patients with more extensive fistulas have been refractory to complete occlusion by embolization and subsequently required surgery, resulting in an inferior outcome in this 
group. Thus, a patient (\#9) with an extensive SDAVF that already presented with severe symptoms and was operated two times after embolization due to recurrence of the fistula showed neurological deterioration after treatment.

Our results are in accordance with the data from the majority of previously reported studies, indicating that surgical treatment results in a more favorable outcome. There is still a considerable failure rate of $23.5 \%$ for the group of patients who were primarily selected for endovascular treatment. However, even if the morbidity of surgery is low, it represents a more invasive procedure than endovascular treatment. As the diagnosis of SDAVF is made at an average age of 62 years [9], unfavorable preoperative conditions in elderly and multimorbid patients are common and have to be taken into account in the decision-making process. Given that a selective spinal angiography has to be performed for diagnostic reasons in either case and the interventional morbidity is low in experienced hands [51], we recommend attempting endovascular occlusion of the SDAVF during the same session if the lesion seems amenable with a reasonable success rate and a low risk of complications. Thereby, the best modality of treatment has to be determined on patient-by-patient basis and should be approached by an interdisciplinary team.

\section{Conclusions}

Both endovascular and surgical treatment of SDAVFs resulted in a significant long-term recovery from myelopathic symptoms and in an improvement in general quality of life in the majority of the treated patients. In cases when endovascular treatment failed and a secondary neurosurgical approach was required to achieve complete occlusion of the SDAVF, the clinical outcome was rather poor. In our opinion, the optimal first-line treatment strategy for each individual patient should be determined by an experienced interdisciplinary team.

In addition, it has to be emphasized that the recovery of clinical symptoms was incomplete in many patients because the diagnosis was established too late and the patients already presented with severe and long-lasting neurological deficits. The diagnostic difficulty remains a main problem in the management of this rare disease.

Conflict of interest statement We declare that we have no conflict of interest.

\section{References}

1. Kendall B (1986) Spinal angiography with iohexol. Neuroradiology 28:72-73
2. Hurst RW, Kenyon LC, Lavi E, Raps EC, Marcotte P (1995) Spinal dural arteriovenous fistula: the pathology of venous hypertensive myelopathy. Neurology 45:1309-1313

3. Jellema K, Canta LR, Tijssen CC, van Rooij WJ, Koudstaal PJ, van Gijn J (2003) Spinal dural arteriovenous fistulas: clinical features in 80 patients. J Neurol Neurosurg Psychiatry 74:14381440

4. Kohno M, Takahashi H, Ide K, Ishijima B, Yamada K, Nemoto S (1996) A cervical dural arteriovenous fistula in a patient presenting with radiculopathy. Case report. J Neurosurg 84:119123

5. Koch C, Gottschalk S, Giese A (2004) Dural arteriovenous fistula of the lumbar spine presenting with subarachnoid hemorrhage. Case report and review of the literature. J Neurosurg 100:385-391

6. Hassler W, Thron A, Grote EH (1989) Hemodynamics of spinal dural arteriovenous fistulas. An intraoperative study. J Neurosurg 70:360-370

7. Koenig E, Thron A, Schrader V, Dichgans J (1989) Spinal arteriovenous malformations and fistulae: clinical, neuroradiological and neurophysiological findings. J Neurol 236:260-266

8. Koch C (2006) Spinal dural arteriovenous fistula. Curr Opin Neurol 19:69-75

9. Gilbertson JR, Miller GM, Goldman MS, Marsh WR (1995) Spinal dural arteriovenous fistulas: MR and myelographic findings. AJNR Am J Neuroradiol 16:2049-2057

10. Partington MD, Rufenacht DA, Marsh WR, Piepgras DG (1992) Cranial and sacral dural arteriovenous fistulas as a cause of myelopathy. J Neurosurg 76:615-622

11. Rosenblum B, Oldfield EH, Doppman JL, Di Chiro G (1987) Spinal arteriovenous malformations: a comparison of dural arteriovenous fistulas and intradural AVM's in 81 patients. J Neurosurg 67:795-802

12. Jellema K, Tijssen CC, Fijnheer R, de Groot PG, Koudstaal PJ, van Gijn J (2004) Spinal dural arteriovenous fistulas are not associated with prothrombotic factors. Stroke 35:2069-2071

13. Rizvi T, Garg A, Mishra NK, Gaikwad SB, Gupta V (2006) Metachronous double spinal dural arteriovenous fistulas. Case report and review of the literature. J Neurosurg Spine 4:503-505

14. Krings T, Lasjaunias PL, Hans FJ, Mull M, Nijenhuis RJ, Alvarez H, Backes WH, Reinges MH, Rodesch G, Gilsbach JM, Thron AK (2007) Imaging in spinal vascular disease. Neuroimaging Clin N Am 17:57-72

15. Sibon I, Menegon P, Tafer N, Dousset V (2006) Diffusion MRI in spinal dural arterio-venous fistula: a case report. Spinal Cord 44:315-317

16. Binkert CA, Kollias SS, Valavanis A (1999) Spinal cord vascular disease: characterization with fast three-dimensional contrastenhanced MR angiography. AJNR Am J Neuroradiol 20:1785-1793

17. Farb RI, Kim JK, Willinsky RA, Montanera WJ, terBrugge K, Derbyshire JA, Van Dijk JM, Wright GA (2002) Spinal dural arteriovenous fistula localization with a technique of first-pass gadolinium-enhanced MR angiography: initial experience. Radiology 222:843-850

18. Van Dijk JM, TerBrugge KG, Willinsky RA, Farb RI, Wallace MC (2002) Multidisciplinary management of spinal dural arteriovenous fistulas: clinical presentation and long-term follow-up in 49 patients. Stroke 33:1578-1583

19. Zampakis P, Santosh C, Taylor W, Teasdale E (2006) The role of non-invasive computed tomography in patients with suspected dural fistulas with spinal drainage. Neurosurgery 58:686-694

20. Oldfield EH, Di Chiro G, Quindlen EA, Rieth KG, Doppman JL (1983) Successful treatment of a group of spinal cord arteriovenous malformations by interruption of dural fistula. J Neurosurg 59:1019-1030

21. Nichols DA, Rufenacht DA, Jack CR Jr, Forbes GS (1992) Embolization of spinal dural arteriovenous fistula with polyvinyl 
alcohol particles: experience in 14 patients. AJNR Am J Neuroradiol 13:933-940

22. Steinmetz MP, Chow MM, Krishnaney AA, Andrews-Hinders D, Benzel EC, Masaryk TJ, Mayberg MR, Rasmussen PA (2004) Outcome after the treatment of spinal dural arteriovenous fistulae: a contemporary single-institution series and meta-analysis. Neurosurgery 55:77-87

23. Sherif C, Gruber A, Bavinzski G, Standhardt H, Widhalm G, Gibson D, Richling B, Knosp E (2008) Long-term outcome of a multidisciplinary concept of spinal dural arteriovenous fistulae treatment. Neuroradiology 50:67-74

24. Guzman R, Dubach-Schwizer S, Heini P, Lovblad KO, Kalbermatten D, Schroth G, Remonda L (2005) Preoperative transarterial embolization of vertebral metastases. Eur Spine J 14:263-268

25. Song JK, Gobin YP, Duckwiler GR, Murayama Y, Frazee JG, Martin NA, Vinuela F (2001) N-butyl 2-cyanoacrylate embolization of spinal dural arteriovenous fistulae. AJNR Am J Neuroradiol 22:40-47

26. Aminoff MJ, Logue V (1974) The prognosis of patients with spinal vascular malformations. Brain 97:211-218

27. Vanswieten JC, Koudstaal PJ, Visser MC, Schouten HJA, Vangijn J (1988) Interobserver agreement for the assessment of handicap in stroke patients. Stroke 19:604-607

28. Morimoto T, Yoshida S, Basugi N (1992) Dural arteriovenous malformation in the cervical spine presenting with subarachnoid hemorrhage: case report. Neurosurgery 31:118-120

29. Atkinson JLD, Miller GM, Krauss WE, Marsh WR, Piepgras DG, Atkinson PP, Brown RD Jr, Lane JI (2001) Clinical and radiographic features of dural arteriovenous fistula, a treatable cause of myelopathy. Mayo Clin Proc 76:1120-1130

30. Thron A (2001) Spinal dural arteriovenous fistulas. Radiologe 41:955-960

31. Aminoff MJ, Barnard RO, Logue V (1974) The pathophysiology of spinal vascular malformations. J Neurol Sci 23:255-263

32. Oldfield E (1998) Spinal vascular malformations. In: Swash M (eds) Outcomes in neurological and neurosurgical disorders. Cambridge Univ. Press, Boston, p 134-155

33. Bradac GB, Daniele D, Riva A, Bracchi M, Stura G, Riccio A, Pagni CA (1994) Spinal dural arteriovenous fistulas: an underestimated cause of myelopathy. Eur Neurol 34:87-94

34. Jellema K, Tijssen CC, Sluzewski M, van Asbeck FW, Koudstaal PJ, van Gijn J (2006) Spinal dural arteriovenous fistulas-an underdiagnosed disease. A review of patients admitted to the spinal unit of a rehabilitation center. J Neurol 253:159-162

35. McCutcheon IE, Doppman JL, Oldfield EH (1996) Microvascular anatomy of dural arteriovenous abnormalities of the spine: a microangiographic study. J Neurosurg 84:215-220

36. Huffmann BC, Gilsbach JM, Thron A (1995) Spinal dural arteriovenous fistulas: a plea for neurosurgical treatment. Acta Neurochir (Wien) 135:44-51
37. Symon L, Kuyama H, Kendall B (1984) Dural arteriovenous malformations of the spine. Clinical features and surgical results in 55 cases. J Neurosurg 60:238-247

38. Afshar JK, Doppman JL, Oldfield EH (1995) Surgical interruption of intradural draining vein as curative treatment of spinal dural arteriovenous fistulas. J Neurosurg 82:196-200

39. Watson JC, Oldfield EH (1999) The surgical management of spinal dural vascular malformations. Neurosurg Clin N Am 10:73-87

40. Ushikoshi S, Hida K, Kikuchi Y, Miyasaka K, Iwasaki T, Abe H (1999) Functional prognosis after treatment of spinal dural arteriovenous fistulas. Neurol Med Chir (Tokyo) 39:206-212

41. Niimi Y, Berenstein A, Setton A, Neophytides A (1997) Embolization of spinal dural arteriovenous fistulae: results and follow-up. Neurosurgery 40:675-682

42. Song JK, Vinuela F, Gobin YP, Duckwiler GR, Murayama Y, Kureshi I, Frazee JG, Martin NA (2001) Surgical and endovascular treatment of spinal dural arteriovenous fistulas: long-term disability assessment and prognostic factors. J Neurosurg 94:199-204

43. Guillevin R, Vallee JN, Cormier E, Lo D, Dormont D, Chiras J (2005) N-butyl 2-cyanoacrylate embolization of spinal dural arteriovenous fistulae: CT evaluation, technical features, and outcome prognosis in 26 cases. AJNR Am J Neuroradiol 26:929-935

44. Westphal M, Koch C (1999) Management of spinal dural arteriovenous fistulae using an interdisciplinary neuroradiological/ neurosurgical approach: experience with 47 cases. Neurosurgery 45:451-457

45. Schick U, Hassler W (2003) Treatment and outcome of spinal dural arteriovenous fistulas. Eur Spine J 12:350-355

46. Nagata S, Morioka T, Natori Y, Matsukado K, Sasaki T, Yamada $T$ (2006) Factors that affect the surgical outcomes of spinal dural arteriovenous fistulas. Surg Neurol 65:563-568

47. Deen HG Jr, Nelson KD, Gonzales GR (1994) Spinal dural arteriovenous fistula causing progressive myelopathy: clinical and imaging considerations. Mayo Clin Proc 69:83-84

48. Jellema K, Sluzewski M, van Rooij WJ, Tijssen CC, Beute GN (2005) Embolization of spinal dural arteriovenous fistulas: importance of occlusion of the draining vein. J Neurosurg Spine 2:580-583

49. Cognard C, Miaux Y, Pierot L, Weill A, Martin N, Chiras J (1996) The role of $\mathrm{CT}$ in evaluation of the effectiveness of embolisation of spinal dural arteriovenous fistulae with N-butyl cyanoacrylate. Neuroradiology 38:603-608

50. Britz GW, Lazar D, Eskridge J, Winn HR (2004) Accurate intraoperative localization of spinal dural arteriovenous fistulae with embolization coil: technical note. Neurosurgery 55:252-254

51. Jellema K, Tijssen CC, van Rooij WJ, Sluzewski M, Koudstaal PJ, Algra A, van Gijn J (2004) Spinal dural arteriovenous fistulas: longterm follow-up of 44 treated patients. Neurology 62:1839-1841 